\title{
The Notion of Regulation in Internacional Law
}

\author{
Luiz Ricardo Miranda * \\ Tomás Olcese **
}

\begin{abstract}
Regulation - a notion first borrowed from the natural sciences by economists and then from economists by lawyers - has become increasingly common in international law. Within this article, we attempt to define the main features of international regulation. To do so, we will retrace, although not exhaustively, the path of the successive applications of this notion through its implementation in two major legal models. This will be a necessary step in defining its distinctive criteria. Thereafter, we will analyze the feasibility of employing these criteria into international regulation to determine whether the phenomenon observed within domestic legal systems is actually the same phenomenon or a completely different one.
\end{abstract}

Keywords: Regulation; International regulation; International law.

\section{Resumen}

La regulación, una noción tomada primero de las ciencias naturales por los economistas y luego de los economistas por los abogados, se ha vuelto cada vez más común en el derecho internacional. En este artículo, intentamos definir las características principales de la regulación internacional. Para esto, volveremos sobre, aunque no exhaustivamente, el camino de las aplicaciones sucesivas de esta noción a través de su implementación en dos modelos legales principales. Este será un paso necesario para definir sus criterios distintivos. Posteriormente, analizaremos la viabilidad de emplear estos criterios en la regulación internacional para determinar si el fenómeno observado en los sistemas legales nacionales es en realidad el mismo fenómeno o uno completamente diferente.

Palabras claves: Regulación; Regulación internacional; Derecho internacional.

\footnotetext{
* Professor of International Law. Ph.D. in Public International Law - University of São Paulo (Brazil). Ph.D. in Development studies - University of Nice (France). International Visiting scholar at American University - Washington College of Law (2012). Email: luizricardo.miranda@gmail.com. Received: March 18th 2019; accepted: September 25th 2019.

** Professor of Roman law, Civil law and International relations. Ph.D. in Civil Law -University of São Paulo (Brazil). Master degree in Civil law - University of São Paulo (Brazil).
} 
Luiz Ricardo Miranda, Tomás Olcese

The Notion of Regulation in International Law

\section{Introduction}

The starting point of this work were various discussions held for the purpose of devising new strategies to teach current international economic law. During the discussions, references arose to an apparently well-established notion of international regulation. As a result, questions emerged on the content of the legal notion of regulation, but, somewhat unsurprisingly, no satisfactory answer ever emerged.

The relevance of the topic was reinforced through subsequent research, especially in the context of project finance. Being aware of its controversial content, we did not attempt to establish an exclusive definition, which was beyond the scope of our work, nor explore any other approach, but only identify the specific meaning of the term within that work to avoid any conceptual misunderstandings during the discussion. Once again, it was unsurprising that some members of the jury had assumed very different conceptions of regulation: while some adopted a very broad definition by expanding the idea of regulation far beyond law, others restricted it to the legal field.

Indeed, we do not believe there is a right or wrong definition in this debate, only two distinctive conceptions of law itself as a phenomenon. From these different understandings, two facts emerge: (1) there is no consensus on the content of the term international regulation; (2) notwithstanding its vagueness, the growing use of this term has been seen within a large range of different circumstances, turning it into a puzzle with varied features. However, this lack of an established definition could provoke communication problems and basic misunderstandings.

In opting for the broadest possible notion of regulation, which encompasses legislation and also nonlegislative regulation, a choice that will be justified throughout this work, we aim to address precisely these problems, primarily by indicating the serious issues that this terminological vagueness may cause. Since no paradigm exists that can serve as a reference for the development of the notion of regulation within the international sphere, we methodologically opt to retrace the origins of this term in domestic systems by starting with its use in economics, where the term first appeared, then exploring its applications in domestic law systems and international law. Throughout this paper, which is not intended to furnish an exhaustive analysis of the theories of regulation, we will define the main features of regulation within domestic legal systems to highlight the incongruence and obstacles presented by the mere transplantation of this notion to international law.

\section{The Notion of Regulation in Domestic Legal Systems}

The concept of economics arises from the intersection of two crucial vectors: limited human needs and the scarcity of available resources to satisfy them. Accordingly, since the object of economics is the management of these resources, economics itself may be succinctly defined as the administration of scarcity (Nusdeo, 1995). 
Although economic theory stresses the prevalence of free market forces in the spontaneous organization of such management, whenever and wherever regulation is attempted the use of legal instruments is commonplace. However, this does not mean that the utilitarian principle that typically drives the relationship between law and economics defines the role of either discipline. While the creation of rules can be one of the main instruments for the normative organization of economic relations, this is not the only way the government can realize this task. Similarly, while most of the social relations regulated by law are economic in nature, laws can be also used to protect legal interests that lack economic relevance. Graphically, we could illustrate this as two largely, but not completely, overlapping circles. From this point, an intuitive question drives us to the next level: if the government organizes the management of scarce resources within the domestic system, which criteria (or mechanisms) are employed to do this?

The liberal market-focused system has resulted in a model that attempts to separate politics and economics as much as possible (Nusdeo, 1995). In this model, the political sphere handles the organic functions of government action, while the market organizes economic relations. This theoretical formulation, which gave birth to the liberal state model in the $17^{\text {th }}$ and $18^{\text {th }}$ centuries, inevitably faced the practical problems of balancing the political and economic spheres, which became ever more frequent over time. The natural evolution of society, with the proliferation of social demands and the discovery of the limitations of the market as an arbitrator, has led to government interference in the economic domain, an element that intensified the points of intersection between economics and politics. This has generated a kind of mixed (or dual) system, characterized as being more or less interventionist.

This consolidation of the private (market)/public (government) dichotomy has resulted in economic decisions that follow very different lines of thinking and has, therefore, intertwined economics with politics, creating a gray zone where no clearly identifiable boundary separates the two domains. It is within this loosely defined sphere of government action, where one can detect two correlated (but unmistakably identifiable) sides of its action-suppression of dysfunctional market mechanisms and the realization of political goals through economic activity—, that regulation arises.

One can attribute a significant part of the misunderstandings regarding the notion of regulation to semantics. Salomão Filho (2008) notes that the term, sometimes equated with self-regulation, others with deregulation, may indeed encode a diverse range of meanings and frequently lack precision.

Despite semantic similarities that could relate regulation to either the creation or suppression of rules, the original notion of regulators, and consequently of regulation, did not have legal roots. By the $18^{\text {th }}$ century, the term "regulator" in the natural sciences designated an external system of command to stabilize a constant, i.e., a regulator of speed or temperature (thermostat) (Chevallier, 2004). American scholarship, for its part, applied the notion of external market regulation and set out to idealize a mechanism designed to correct market failures. The existence of such a mechanism was justified by a vague notion of social welfare. This early notion of market regulation was subsequently transplanted to law, where it had to confront the conceptual limitations of legal thought: the dilemma over the definition of the term by jurists is believed to have emerged from its successive interdisciplinary adaptation.

According to Glaeser \& Andrei (2003), through the late $19^{\text {th }}$ century, commercial disputes in the United States were predominately resolved by tribunals. During this period, the use of regulatory measures was unusual, regulatory agencies were almost nonexistent, and any inclination toward regulation was 
Luiz Ricardo Miranda, Tomás Olcese

The Notion of Regulation in International Law

immediately considered a threat to contractual freedom and thus rejected: "There is no reasonable ground for interfering with the liberty of person or the right of free contract, by determining the hours of labor, in the occupation of a baker" (Lochner v. New York, 1905). This scenario was quite logical and well adapted to the country's reality as an economy founded in the agrarian sector (in 1850, 64\% of all employees were located in farms), whose manufactured products were produced by small enterprises. Under these circumstances, corruption was not an economically viable option, and eventual market failures did not pose a significant risk to customers.

By the turn of the century, the country's economic profile had drastically changed. Agriculture at this point comprised $37 \%$ of all workers, having lost ground to the flourishing of industries. In this extraordinary explosion of large enterprises, the economic and political asymmetry among them and other judicial counterparts increased. The courts, confronted by large corporations' economic and political power, became more susceptible to their influence. At the same time, the virtual concentration of power within certain sectors of the market intensified the risk of market failures. In this scenario, regulatory agencies, either federal or local, increasingly played the role once occupied by courts and state entities in the regulation of most distinct subjects: antitrust, transport by rail, and sanitary standards, among others. Started by local administrations, this revolution spread throughout the country. In 1887, the Interstate Commerce Act established a commission (the Interstate Commerce Commission), and the Sherman Act, in 1890, established restrictions to trusts. The intensification of regulatory activity reached its highest point at the beginning of the $20^{\text {th }}$ century during Theodore Roosevelt's and Woodrow Wilson's administrations.

Curiously, the initial theories attempting to explain regulation adopted a highly critical approach to its justification. For instance, the neoclassical school of economics was characterized by its skepticism of both the real impact of regulation on monopolies (Glaeser \& Andrei, 2003), and its real purposes. Among its most influential practitioners, Demsetz (1968) was the first one to invert the established logical equation by suggesting that regulation did not serve to protect public interest but corporate interests instead. Stigler (1971) adopted the same premise to further investigate how regulation facilitated and even promoted private corporate interests. The discussions and findings in these two earlier works were incorporated into the capture theory posited by Posner (1974). From the perspective of Brazilian legal scholarship, Nusdeo (1995) is particularly sharp in stating that the market, its failures notwithstanding, is preferable to government intervention in the economic domain, given the distortions it can provoke. Considering the inherent inefficiency of government-run economic activities when compared to the market, the neoclassical school promoted deregulation policies as well as the use of self-regulating mechanisms.

The neoclassical school's well-established position is permeated by an attitude of resignation regarding an apparently insoluble dilemma: the choice between market failure and distortions caused by government intervention. The more conscientious neoclassical theoretical construction that followed earlier thought was intended to provide a functional analysis of the public sector's deficiencies. By softening the negativity and ultraliberal rhetoric that characterized the first stage of public choice, neoclassical concerns evolved into an attempt to seek a better balance between the two types of economic decision-making by consolidating institutional instruments capable of promoting a more efficient connection between the political domain and the market. 
The neoclassical concept of regulation, based almost exclusively on a market perspective, cannot be understood outside the historically determined context of the United States. It is neither a universal intuition nor a paradox, but a phenomenon that is inextricably related to that country's legal system and history. The synergy between the United States legal system and capitalism seems to have produced a specific model of government that is well suited to the development of economic liberalism. At the core of the American legal system's penchant for ex-post regulation is the country's specific federalist, constitutional, and decentralized model of government, which envisions the state as a partner to realize the liberal purposes of free market agents. Within this context, the conception of law as an instrument that serves free-market economic interests sits well with the fundamental values that have always animated that society.

The model of regulation conceived in the United States acquired new features when transplanted to continental Europe. The exclusively economic notion of regulation, which was limited to the correction of market failures by means of regulatory instruments, had to be reconciled with the legal institutions of civil law and administrative law, as well as with the notion of public service. In the European context, the original scope the American system had assigned to regulation was modified in order to reflect the transition from a welfare to a neoliberal state. From this perspective, it seems impossible to dissociate regulation from the welfare state crisis. Placing regulation at the core of the emerging conception of neoliberal government resulted in a radical mutation of the very structure of government, as its role gradually shifts from active economic agent to systemic manager of economic activity (Chevallier, 2001).

The material concerns that drove Americans and continental Europeans to adopt the so-called regulatory model are very different. As previously mentioned, the use of regulation in the United States was a response to the perceived inefficiency of the courts and the public administration in neutralizing market distortions. While the very limited welfare state experience in the United States did not implicate any financial impact on the country's public finances, the adoption of regulation and the breakdown of the welfare state are inseparable events in European countries. In fact, the more superficial discrepancies between these two models seem rooted in a far more profound difference: the bureaucratic rationality of the state in continental Europe (as conceived by Weber), as opposed to the logic of the market, symbolized by the homo oeconomicus, in the United States (as conceived by the theory of competition). Each approach is guided by different underlying principles: the theory of the state is founded on the idea of general interest (or the common good), while the theory of the market rests on the notion of general balance (or perfect competition) (Timsit, 2004). Curiously, such differences did not prevent the emergence of fairly similar government structures in the various countries that adopted one approach or the other.

The widespread use of regulation could give the impression that the regulatory state model has become universal. Conceptually imprecise as the term "regulatory state" may be, one can indeed note some very broad features of this new model. It was developed in the United States in order to correct market failures, it inevitably came to incorporate, once transplanted into mainland Europe, the notion of public service inherent to the conception of state in most European countries. The proliferation of regulatory agencies seen in France during the last decades clearly reveals this tendency in Europe. Although the arguments that led to the widespread adoption of the regulatory model in Europe have varied significantly, the economic pressure toward state reform has undoubtedly been a common element. 
Luiz Ricardo Miranda, Tomás Olcese

The Notion of Regulation in International Law

Alongside the efforts to define the features of this new state model, some have posited that it amounts to nothing more than a globalized form of the American model (Kelemen \& Sibbitt, 2004). Despite the undeniable logic behind some of those arguments, such a generalization does not accurately describe the complexities involved.

Granted, neither the origins of the theoretical framework on which the modern conception of regulation is based nor the adoption of some form of regulation in various legal systems can be denied. However, regulation in continental Europe has ventured so far from the original model that one ought to question whether it is, in fact, the same phenomenon. The strongest argument against conceiving regulation as a globalized version of American law rests on the fact that regulation, in all of its forms, has experienced subtle mutations over time. Indeed, what seems to have emerged is not the supremacy of a particular national system but a continuous process of convergence between different systems. Therefore, while the gradual dismantling of the welfare state in continental Europe meant an evident change in features as they were conceived in those states (Sundfeld, 1999), mutations also occurred both in England and in the United States. In England, the proliferation of statutes, particularly as part of the European construction, has had considerable impact on the inherent logic of English law. In the same way, a considerable number of state interventions have subverted the liberal logic that has always guided American society. Within this context, references to the New Deal during the last economic crisis (2008) have inspired plans of action guided toward economic intervention. Seen from this perspective, the originally market-centered regulation of economic activity has become state-centered.

Therefore, we posit that the rationality of the regulatory state is situated midway between state and market rationality and that its peculiar contours are the result of its historical development. Thus, the regulatory state evolved along historical lines, following the pattern of development of earlier state models. In this particular case, the driving force of this process was the intense economic pressure exerted by various economic agents. From this viewpoint, the gradual blurring of the lines between the private and the public economic spheres was perceived as state disengagement or even a crisis of the state.

While Timsit (2004) may be correct in implying the collapse of the "classic model", the scope of the crisis must be put in proper perspective. Although market expansion into domains formerly held by the state is a well-known phenomenon, it does not entail across-the-board disengagement or even weakening of the state. Despite the market's alleged self-sufficiency, the state remains an essential component of its proper functioning. In fact, the market/state symbiosis was already perceptible even when the liberal state was in full swing (Poggi, 1981).

The explanation behind this association is relatively straightforward. According to Salomão Filho (2008), empirical analysis reveals that despite its well-known efficiency, the market is beset by equally clear limitations. While the market is perfectly capable of efficient resource allocation in some areas of the economy, other areas are naturally impervious to adequate allocation by free market forces. For instance, externalities (costs incurred by or benefits accrued to third parties that are not reflected in the price of goods or services) in the social sector demonstrate the inability of market rationality to either compensate or reward these distortions. To address this externality, one must engage in some form of wealth redistribution. Thus, it is immaterial whether overall wealth ultimately increases or not, because the social relevance of making adjustments to compensate for inequalities is paramount. Evidently, the private 
sector would hardly be able to make such adjustments on its own, and if it ever did, it would not be able to avoid producing negative distributive effects.

The advent of regulation has also prompted substantial transformation in the legal sphere. Regulatory instruments are characterized by their lightness, malleability, and pragmatism, emphasizing dissuasion over repression. However, competition between these new instruments and black-letter law do not render the presence of the state any less necessary. Dissuasion has its limitations, which makes the use of legal coercion an indispensable, albeit less frequent, element of regulation (Campilongo, 1999).

To sum up, despite the many questions surrounding the meaning and significance of the "regulatory state" phenomenon, the core idea ultimately points to a government structure marked by decentralization and administrative de-concentration. At the center of this structure, the state functions as an impartial and superior instance of regulation whose purpose is to bring unity out of diversity, homogeneity out of heterogeneity, and order out of chaos (Chevallier, 2001).

\section{Regulation in the International Context}

This concise overview of the development of regulation within domestic legal systems provide distinctive criteria that can help clarify its nature by identifying common elements that span both its original American manifestation and its adapted European form. Therefore, despite the differences between these systems, it seems possible to pinpoint a few distinctive elements that allow us to classify those experiences as a priori expressions of the same broad phenomenon.

The first of these elements is linked to the very conception (originally technical) of regulation. According to Chevallier (2004), natural scientists were the first to identify external location as an essential feature of regulators. The borrowed notion of regulation used by social scientists maintains this characteristic: the state was identified as a body outside the market, making it the natural candidate for the position of regulator.

Adopting liberal market policies does not undermine the regulatory function of the state. Allowing the market to self-regulate does not imply abdication of the prerogative to organize specific economic domains. Moreover, pursuing liberal market policies remains a political choice and therefore a very concrete expression of the power to regulate. Similarly, the presence of a powerful actor in a specific segment of the market does not invalidate this assumption. Although the existence of one or more quasimonopolies in a given market segment may throw doubt as to the identity of the de facto regulatormainly in sectors subject to self-regulation or where regulation is loose-, there is a crisp line that separates the various private economic agents in any given market and its legally designated regulator, even when the latter is negligent or for some reason unable to exercise factual regulatory power. The existence of a specific economic agent with market power is a clear manifestation of market failure, not an expression of any parallel regulatory power.

Another common element identified in each of the different systems analyzed is the parsimonious use of regulation in the economic domain. This is a stable feature of regulation, regardless of whether the regulatory model adopted is more or less interventionist. Consequently, the use of regulation as the sole instrument for addressing public interest is ruled out. Regulation lies precisely at the intersection between 
political and market rationality. Despite the forecasts of market encroachment into the public domain, some areas have a logic of their own and are simply immune to the dynamic of a free market. Environmental protection is a case in point. While environmentally protective action may be induced via the market, the environment remains an area (ideally) located outside the market. Thus, it must be protected by unequivocal legal rules guided by a different rationality. In other words, while the rationality orienting environmental protection can (and should) be considered when economic interests are at stake, economic rationality guided by the quest for the highest possible benefit at the lowest possible cost is unable to ensure environmental protection.

The hybrid nature of the instruments used to effect regulation has repercussions even in the legal domain. Although legal rules (hard law) remain indispensable instruments of regulatory action, some sectors are regulated through inductive policies that lack any legal character. Therefore, one of the common features of any form of regulation is the softness, flexibility, and pragmatism of regulating instruments, notwithstanding the limitations of inductive policies.

International regulation shares clear similarities with its domestic counterpart. At first glance, their affinity suggests that they are nothing but variations of the same phenomenon. However, a closer look reveals inevitable contrasts that rule out a common nature.

From a structural perspective, the reality of international regulation is indeed fairly similar to that of domestic regulation. For instance, one can easily point to the same heterogeneity of regulatory instruments, a problem intensified in the international sphere because of the lack of a transnational authority with natural jurisdiction over the states. Despite several theories on the real motivation of public agents, the loss of national autonomy resulting from the diversification of centers of power seems, in this case, quite clear. As Campilongo (1999) indicates:

[...] globalization - despite its apparent detachment from politics - has transformed states, political parties, parliaments, opposition, and elections into spaces to be occupied for reasons unrelated to efficiency in a global society; politics has simply been displaced. And this creates a problem: detached from state politics and created with a particular theory about democracy in mind, these new political spaces are not always concerned with upholding nor enforcing the highly complex rules of democracy. Such capitis deminutio threatens key players and minor actors alike, blurring the lines between politics and the law (p. 89-90).

From this formal perspective, the proliferation of quasi-legal instruments (a tenuous designation for nonlegal instruments) that often complement and even replace classical legal instruments of international law somehow replicates the same phenomena seen domestically, the only difference being that it is far more commonplace internationally.

It is hardly deniable that the obstacles that hinder the consolidation of international law are considerably greater than those encumber the consolidation of domestic law. Political circumstances and technical issues can render the classical legal instruments of international law unavailable or ineffective. In these cases, regulation by means of "soft law" can be very useful for establishing basic standards of organization (Gold, 1979). Moreover, in several cases, these devices may be applied as a preliminary step in the lengthy process of consolidation of law by formal instruments (Cassese, 2005). Therefore, one could assert that 
the problem is not the existence of these tools themselves, but their promiscuous use or worse, their misuse as something they are not.

The indiscriminate substitution of classical legal instruments of international law with paralegal instruments raises important concerns, primarily in that it expands the gray area that separates one from the other. As noted by Villary (1981), close observation of the contemporary international environment reveals the increasing difficulty of separating actual law from what only appears to be law. Another disturbing consequence of this phenomenon is the creation of paralegal means of standardizing behaviors in direct competition with ordinary methods of creating law, in what amounts to a clear attempt to relieve states or their international obligations, which would not be the case if these engagements were made through formal legal instruments. When considered as a whole, these factors constitute a material and structural obstacle to the consolidation of a rational and effective regulatory framework.

As we have seen, the notion of regulation rests the concept of a regulator that is external to the system to be stabilized. Nevertheless, while the state can fulfill this role in a domestic system, the absence of a natural and definitive transnational authority poses a serious difficulty on an international level. Besides, some entities, such as international organizations charged with international regulation in some sectors, are not entirely outside the sector to be regulated, but are often agents within it. A serious consequence of this is a lack of legitimacy to exercise regulatory power.

The second obstacle faced by international regulation derives from the same inherent weakness of the international system as a whole. The identification of an entity situated outside the market obviously depends on defining the extent of the market itself, and one can only identify what is outside any given market when the precise boundaries of this market have been established. In other words, the regulation of any market presupposes its delimitation. As noted by Grau (2008), the market is a legal entity and thus defined by law. Borrowing from Irti \& Azzariti 1998, he describes the market not as a spontaneous or natural institution-locus naturalis-, but one that is created through specific institutional reforms and is founded on legal rules that regulate, define and shape it. The market, in this sense, is a locus artificialis (Grau, 2008). When transplanted to the international sphere, this problematic definition of the market assumes additional features.

In the same way that domestic regulation requires the existence of an internal market, global regulation depends on the existence of a global market. In this regard, the strategy of assigning regulatory functions to international organizations has had mixed results. For instance, the recurrent derogations and the apparent deadlock on some issues do not prevent the WTO from being referred to as a system, because one can clearly identify a working system in the area of international trade. By contrast, it is much more difficult to pinpoint a regulator when a naturally transversal sector is involved (i.e. environmental matters or international competition) or when a compartmented sector is at stake. In these cases, competition between various organization and the lack of coordination among them typically hinder the establishment of a coherent regulatory framework that meets the minimum requirements of homogeneity and efficiency.

Furthermore, the generic denomination "international organization" covers a wide variety of entities with very disparate purposes, structures and operational instruments. This does not facilitate the creation of a general theory about them. In any case, despite the convenience of being able to appeal to a general 
Luiz Ricardo Miranda, Tomás Olcese

The Notion of Regulation in International Law

theory of international organizations, we believe a general theory would be unhelpful in this case, because it would be unable to produce either a conclusive definition or a helpful analysis of the regulatory roles that some organizations have. Thus, although international organizations have become important regulatory agents in the international economy, their diversity makes it very difficult to devise scientific criteria that, when met, would categorically validate the claim.

In addition, the very existence of a global market in some sectors is debatable. The international banking and financial markets are examples of this. The process of deregulation, together with the development of new technologies, promoted the interconnection of those markets and internationalized their related activities. However, it is unclear whether these internationalized activities constitute a bona fide global market or simply amount to the sum total of all domestic markets. In any case, the question remains as to how to regulate these sectors globally, or how to determine which values should guide this regulation. The answers to these questions depend on defining criteria that will not only promote the desired features of international regulation, but more importantly, ensure its very feasibility.

The indiscriminate and ambiguous use of the term "regulation" in the context of international law is another issue that deserves attention, especially since the conceptual confusion surrounding the term is not free from manipulation resulting from ideological bias. As a rule, institutions and practices develop in specific social, economic, cultural contexts, and it stands to reason that some of their original meaning may be "lost in translation", so to speak, when transplanted into a different context. Also, one must take into account that international regulation has acquired certain peculiarities in order to cope with its environment, which makes implementing regulation on an international level even more difficult. Another recurrent issue is the use of the term "regulation" in sectors quite distinct from economics. Regulation in the United States and continental Europe, one must bear in mind, has always operated under the assumption that there is a market to be regulated. The absence of a preexistent market is what has led to the crisis of the so-called dual model.

The indiscriminate use of the term "regulation"-which has resulted in the application of an allencompassing notion of regulation in sensitive areas where market logic is often irrelevant-has drawn serious criticism. For instance, in areas such as environmental or human rights protection, regulation cannot and should not be invoked. In other words, basic standards of protection must be fixed through unequivocal legal rules which will, as a last resort, define the boundaries of the market located outside those limits. Apart from domains that do not naturally respond to market forces, other areas that define the very boundaries of economic activity itself must also be left outside the market. Applying the logic of the market in those areas would be a mismatch, as it would entail regulating activities rooted on incompatible values and whose rationality runs counter to the inherent logic of markets.

\section{The Hidden Meaning of "Regulation"}

Although indispensable to the proper functioning of various domestic economic segments, regulation is still defined only tentatively. As such, it has been approached from two different angles. On the one hand, some have given it a strictly legal meaning. On the other, some have given it a more expansive significance that goes beyond its legal meaning, recognizing regulation as a phenomenon that overrides the law. As stated in Broches (1959), "[D] finitions in the abstract are seldom 'right' or 'wrong'; they should rather be evaluated as 'helpful' or 'unhelpful' according to the measure in which they clarify or confuse." In this 
case, even if one cannot categorically point to the wrongness of any of these ideas, one can question their utility. From this viewpoint, the arguments against the first line of thought are evident.

In fact, by attempting to confine regulation to the limits of classical legal instruments, the more restrictive line of thinking ignores various forms of state intervention in the economy through non-legal tools. The Brazilian experience clearly illustrates this: some segments of the market are often regulated by statecontrolled legal entities (e.g., Petrobrás, Banco do Brasil, Caixa Econômica Federal), an anomaly that artificially bypasses the regulatory agencies themselves and subverts the entire regulatory system the state itself sanctioned. This kind of regulation is implemented through instruments whose legal components are residual, if not completely nonexistent. They are, in fact, the result of political choices intended to disguise illegal state interference in the economic domain.

The first approach is unable to accommodate such interventions, as it precludes any discussion regarding legal controls for those interventions or the nature of any new instruments created by state practice but not yet categorized by law. Certainly, ignoring problems situated on the fringes of the law not only fails to make them magically disappear but also provokes other technical distortions.

As long as the law is confined to what one can explain, as long as it is molded into a well-defined conception of the world, not only is the scope of one's analysis automatically narrowed down, but certain actions can be explained away without the need to appeal to legal reasoning. In the international environment, this question, which ultimately concerns the very definition of the (legal) nature of some instruments, takes on a different magnitude.

The essential elements that define human society tend to change over time. Illustratively, Castells (2011) even suggested that intellectual categories forged in the past are inadequate to understand the world today. By applying this idea to international law, one can question, in the same way, the efficiency of certain legal instruments forged in the past to address the many problems created by globalization. Thus, in order to satisfy the increasing needs of our rapidly changing international society, new tools and ways of action have been conceived, even if it meant allowing some principles of international law more flexibility.

Logically, none of this would be so dramatic if we referred to legal models inhabiting parallel and incommunicable universes. However, reality is much more complex. Harmonizing these new instruments and the traditional principles of international law is a very delicate task. Hybrid devices designed to be efficient, those instruments are not easily classified under any traditional category; hence their ambiguous legal nature.

From this perspective, despite the similarities between the domestic and the international regulatory systems, it seems that the use of the term "regulation" in the international context does not stem from any real adaptation of an existing model of regulation, but derives instead from an effort to classify certain non-legal instruments that were created through international practice and did not fit any known category. 
Luiz Ricardo Miranda, Tomás Olcese

The Notion of Regulation in International Law

\section{Conclusion}

Despite its various manifestations in a wide-ranging array of national legal systems, regulation has some identifiable recurrent elements and general features. For one, the economic sector is its domain of operation, despite the different justification adopted in the United States and in continental Europe. Seen either as an instrument charged with correcting market failures or as a tool to protect the public interest in sectors once occupied exclusively by the state, regulation in both cases has always operated on the premise that there is a market to regulate.

The role of regulator has traditionally been assigned to the state, which could delegate this power/mission to a state-controlled agency. At this point, it is important to remember that self-regulation must be understood in this context as a political option: opting to allow the market to self-regulate, particularly in underdeveloped markets, may throw doubt as to the difference between a powerful player and the regulator. Nevertheless, it suffices that once the real regulator begins to operate, such confusion will dissolve. Finally, while legal instruments are mostly used to organize certain markets, the state also uses non-legal inductive tools to fulfill the task.

The use of regulation in the international sphere superficially resembles the same phenomenon seen in the national sphere. After all, the multiplicity and heterogeneity of its sources are common characteristics to both spheres. This conclusion, however, fails upon a more careful analysis.

Even if the propagation of regulatory instruments and their heterogeneity are recurring features in most legal systems, they cannot be interpreted as defining features of regulation. It seems clear that their presence is strong evidence for regulation when other defining criteria are detected, but taken in isolation, these traits are insufficient to define regulation. However, as we could see, other distinctive criteria that characterize regulation in different legal systems do not appear in the international environment; the lack of a uniform definition of international regulatory entities adds to the precarious definition of global markets in several sectors. Thus, we cannot conclude that domestic and international regulation are expressions of the same phenomenon.

In fact, what is detected in the international sphere is a generalized hesitation to categorize new practices of international relations as law. It is true that the expansion of the political sphere into the legal domain has considerably broadened the gray zone separating politics and the law (lex lata and lex ferenda) and has opened up entire new areas of study over the past decades. Confronted with the lack of consensus in international society needed to form conventional legal rules in these so-called sectors, as well as with the incipient maturity of customary law, non-legal political agreements have come to be used to organize them. To avoid technical and ideological controversies over the definition of law in some areas, the term "regulation" has become a semantic walking stick, a convenient empty shell apparently devoid of technical content and of intrinsic ideological value.

In other words, the allegedly neutral term "regulation" actually invokes a very well-defined ideological meaning. The careless (or strategically planned) use of the term regulation in the international sphere seems to be a reflex of a deeper problem in international law: the recognition of the kind of legal limbo caused by the transition from the obsolete classic model to the still conceptually and operationally deficient new model of international action. 
Therefore, our conclusions must be taken as narrowly as the facts available in a well-defined historical moment. Accordingly, the lack of correspondence between the idea of international regulation and regulation in domestic systems does not mean that this conclusion will remain unchanged if circumstances change. If the opposition between those aligned to the theory of the fragmentation of international law and those arguing that this fragmentation is only a natural step toward a broader process of the specialization of international law, does not currently allow us to confirm any of these theories, international law clearly appears to be undergoing a process of normative consolidation. We need to determine whether this process will bring systematic logic to international law or deepen the segmentation of legal subsystems. In the former case, the development of sectors outside the market will be able to apply limits to market logic by naturally defining the zone of effectiveness for regulation; in the latter, the current conceptual confusion will likely persist.

\section{References}

Broches, A. (1959). International legal aspects of the operations of the World Bank. Recueil Des Cours, Collected Courses, Volume 98 (2007), 297-409. doi: 10.1163/ej.9789028613522.297-409

Campilongo, C. (1999). Teoria do direito e globalização econômica. In Direito Global (1st ed.). Brazil: Max Limonad.

Cassese, A. (2005). International law (2nd ed.). Oxford Univ Press.

Castells, M. (2011). Preface. In A Sociedade Em Rede (6th ed.). Sao Paulo: Paz e Terra.

Chevallier, J. (2004). L'état régulateur. Revue française d'administration publique, n¹11(3), 473-482. doi:10.3917/rfap.111.0473.

Chevallier, J. (2001). La régulation juridique en question. Droit et société, 49(3), 827-846. https://www.cairn.info/revue-droit-et-societe1-2001-3-page-827.htm.

Irti, N., \& Azzariti, G. (1998). Il Dibattito sullordine giuridico del mercato (3rd ed.). Roma: Laterza.

Joseph, G., (1979). Legal and Institutional Aspects of the International Monetary System: Selected Essays.

Demsetz, H. (1968). Why Regulate Utilities? The Journal of Law and Economics, 11(1), 55-65. doi: $10.1086 / 466643$

Glaeser, E., \& Andrei, S. (2003). “The Rise of the Regulatory State.” Journal of Economic Literature 41 (2): 401-425.

Kelemen, R. D., \& Sibbitt, E. C. (2004). The Globalization of American Law. International Organization, 58(01). doi: 10.1017/s0020818304581043

Nusdeo, F. (1995). Fundamentos para uma codificação do direito econômico. São Paulo: Ed. Revista dos Tribunais. Poggi, G. (1981). A Evolução do estado moderno: uma introdução sociológica. Rio de Janeiro: Zahar.

Posner, R. A. (1974). Theories of Economic Regulation. The Bell Journal of Economics and Management Science, 5(2), 335. doi: 10.2307/3003113

Salomão Filho, C. (2008). Regulação da atividade econômica: princípios e fundamentos juridicos. São Paulo: Malheiros Ed.

Stigler, G. J. (1971). The Theory of Economic Regulation. The Bell Journal of Economics and Management Science, 2(1), 3. doi: 10.2307/3003160

Sundfeld , C. A., (1999). A administração pública na era do direito global. In Direito Global (1st ed.). Brazil: Max Limonad. 
Luiz Ricardo Miranda, Tomás Olcese

The Notion of Regulation in International Law

Timsit, G. (2004). La régulation: La notion et le phénomène. Revue française d'administration publique, no109(1), 5-11. doi:10.3917/rfap.109.0005.

Villary, M. (1981). propos de «lex ferenda» . In Le droit international-unité et diversité: Mélanges offerts à Paul Reuter (pp. 519-521). Editions A. Pedone. doi: 2-333-00091-9 